\title{
Inḩaltsüberjiłht. Gauptteil.
}

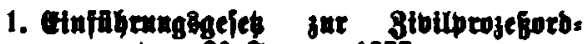
mung bom 30. Samuar $1877 \ldots . . .1$

2. Sibluprozeforbnung in ber faffing bom

8. Sopember 1933.

Borbemertung

Erftes Sud. Allgemeine Beftimmungen.

Erfter 2bidnitt. Beridite.

Erfter Ritel. Sadlide Buftarbigleit . 1-11 9

8toeiter Ritel. Beridtştant ..... 12-37 10

Dritter Eitel. Bereinbarung ûber bie

8uftänbigleit ber Beridte . . . . . 38-40 15

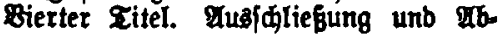

lehnung ber seridtsperfonen . . . 41-49 16

Bweiter פ্bjdnitt. Barteien.

Erfter Zitel. Parteifăbigleit. Prozéb făhigleit . . . . . 50-58 18

8weiter Titel. Streitgenoffenfमaft . . 59-63 20

Dritter Fitel. Beteiligung Dritter am

Pedutaftreit ........ 64-77 20

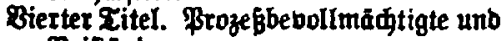

Beifánbe ........ 78-90 24

F̧anfter Titel. Brozesfojten ..... 91-107 26

Sediter Fitel. Siderheitsteifurt. . . 108-113 31

Sieberter Iitel. פ্রmentedt . . . . . 114-127 33 
Dritter 2 bffmitt. Berfabren.

15 Gette

Criter Eitel. gkünblide Berhanblung . 128-165 37 3tweiter Fitel. 8uftellunger:

I. Buftellunger auf Betreiben ber Barteien ........ 166-207 47

II. Buftellungen bon Umts megen . 208-213 56

Dritter Titel. Labungen, Zermine unb Frtifen . . . . . . . . . 214-229 57

Fierter Titel. Folgen der Berfäumung. 2Biebereiniegung in ben vorigen Stand ...........230-23860

Flunfter Fitel. Unterbredung und jekzung bes Berfahreng. . . . 239-252 62

8 weites $B$ u

Erfter gabidnitt. Berfahren bor ben \&and. geriaten.

Eifter Zitel. Berfabren biş zum urteil 253-299 66

8reiter Titel. Urteil . . . . . . . . 300-329 77

Dritter Fitel. Berfäumnis̄urteil . . . 330-347 86

Bicrter Titel. Berfahren bor bem Einzel. ridter . . . . . . . . . 348-350 89

Fünfter Titcl. Qllgemeine Bejtimmungen laber bie Bemeisaufnahme ... 355-370 91

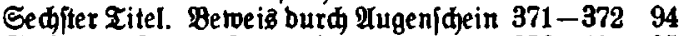

Siebenter Zitel. Beugenberwei3.... 373-401 95

Adter Zitel. Betweis burd Sadberitänbige . . . . . . . 402-414 103

Neunter Zitel. \$emeis Durd Urtunben 415-444 106 Bebnter Fitel. Berweis burd Barteivernebmung. ......... 445-455 111 Ciffer Fitel. Berfahren bei ber $\mathfrak{U}$ b. nabme von Eiben ....... 478-484 114

8 walfter Titel. Siđjerung bes Bemeifes 485-494 115 Bweiter 2 bffinitt. Berfahren bor ben Amtageridten .......4495-510 b 117

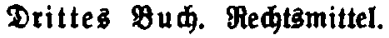

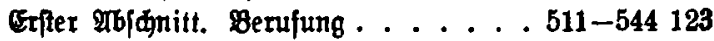




\section{Jingaltsuberidit.}

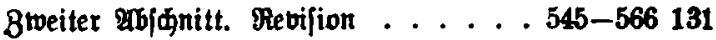

Dritter 20 [dnitt. Befdwerbe . . . . 567-577 138

Biertes Pum. Biederaufuahme beż Ber-

fahrens. . . . . . . . 578-591 140

Fanftes $\$$ ud. Uthunben- und 2 sedifelprozes . . . . . . . . 592-605 144

Sediftes 9 ud. Cheladen. Fefitfellung

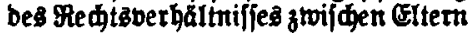
unb Rinbern. Contmütbigungs\}aden.

Erfter 20bidnitt. Berfahten in Egejadten 606-639 147

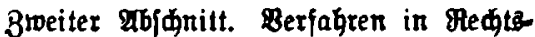
ftreitigleiten, welde bie Gelfftellumg

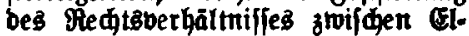
tern unb sinbern zum Bregenftanbe haben .......... 640-644 155

Dritter 2 rbjunitt. Berfabren in Cntmutnbigungasfaden . . . . . 645-687 156

Siebentez $\$$ й. Mahnberfahren . . . 688-703164

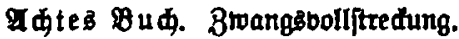

Erfter פbjđnitt. 2algemeine Beftimmungen 704-802 168 8rveiter 26jidnitt. 8wangsodiftredung regen Gelbforberungen.

Erfter Titel. Broangsbollifrectung in bas betveglide Bermogen:

I. arlgemeine Beftimmungen . . . 803-807 191

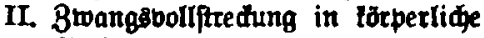
Saden . . . . . . . . . 808-887 193

III. 8wangsbollftredung in Forberutgen uno anbere Bermägens redite . . . . . . . . . . . 828-863 198

Bmeiter Titel. Bwangsbollftrecturng in bas unbetwegride Bermoger . . 861-871 210 
Dritter Zitel. BerteilumgBberfahren . . 872-882 212 Dritter 9b/4nitt. Bwangsbolrjtrechung zur Erwirtung ber Serausgabe bon Sachen unb zur Grtoirtung bon Sanblungen ober Unterlajfungen . 883-898 214 Bierter 201фnitt. Dffenbarungbeib u. \$aft 899-915 217

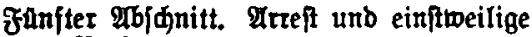

Berfugung . . . . . . . . 916-945 221

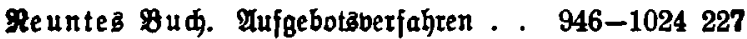

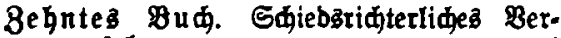

fałren.......... . . 1025-1048 242

3. Gefet, betr. bießeiqlagnahue besqubeitos Dber Stenfilohas bom 21. Suni 1890 .

4. Ceies, betr. bie Bufrubtglett bes Reifis: gextats bom 22. Eat 1010 ......

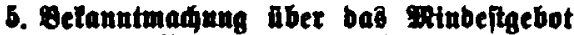
bet ber serfetgernug gepfanbeter Gahen bou 8. Dltober 1914

6. Becorbung Abet gobnofänbung von 25. Sunt 1010 ............. .

7. Cefes aut Enflaping ber Gertigte bom 11. vara 1021 ...........

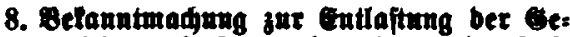
tidite b. 9 . Beptember 1915 in bex 8af: fung vom 13. Wat 1924.

Mahnberfahren bor ben Amtageriøten . . $1-5 \quad 257$

Betwilligung bon Bablunģfriften . . . . 6-6 259

Betfahren bis zum utrteil . . . . . . 7-8 259

urteil unb 8wangsboliftredung . . . . . 9-17 259

Eđ̆iebsెurteil ........... 18-20 262

Solußbotfătift........... 21-21 264

จ. Cefes unt Anbermug bes serfahrens in bits. gethigen fiedisfitettigletten bout 27. Dts tober 1928. . . . . . . . . . 


\section{Inthang.}

Die zibtlprozeffualen Beftimumugen bet stotberorbnungen.

1. Berorbunng bę Mröfibenten jur eidges Eette rung bon sintipaft unb Binanjen; 9. Tetl, Beretufadyungen axf bem Gebiete ber Mediobflege bom 1. Dezember 1020 . .

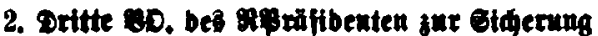
bon sirtidjaft unb gituangen unb jur Bez

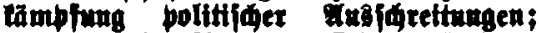
6. Ietr seditopflege Rap. I setetufadung unb Expharkiffe bom 9. Dttober 1081. . .

3. Inpaffungaberorbuung 7. Teil Reditspliege vom 26, Dejember 1081 . . . . . .

4. Berorbung bes menfibenten iber ila $a=$ unguten auf beut Gebtete ber Beditapflege unb Betwaltung, 1. Xetl sereinfadung unb Eriparutlie Rap. II sanerlige redgto: bflege mb sap. II semetuinaftlide sorz idertiten fir Strafreditop pege nub ofingers lide Anestop flege bour 14. Juni 1082 . .

5. Berorbming tber stafualmen auf bem ses biete ber groungboliftediung; VII. Th. idnitt 8toungowollftredung in beweglidge Ceqenfinube bom 26, sitai 1038. . . . .

atpliabettifies Gadreatfier. . . . . . . . 277 
